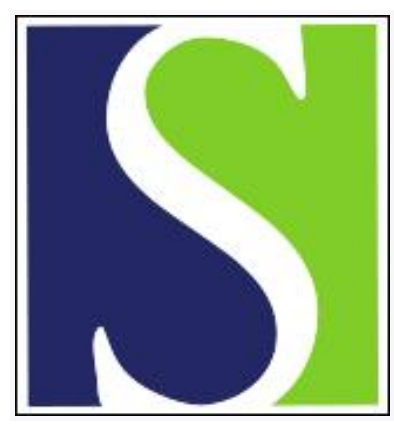

Scand J Work Environ Health 1975;1(3):178-183

https://doi.org/10.5271/sjweh.2848

Issue date: Sep 1975

Electrophysiological studies on rabbits in long-term exposure to carbon disulfide.

by Seppäläinen AM, Linnoila I

Key terms: carbon disulfide; electroneuromyography; electrophysiological study; long-term exposure; neuropathy; rabbit

This article in PubMed: www.ncbi.nlm.nih.gov/pubmed/1228898

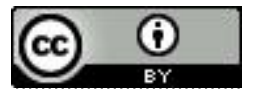




\title{
Electrophysiological studies on rabbits in long-term exposure to carbon disulfide
}

\author{
by ANNA MARIA SEPPÄLÄINEN, M.D., ${ }^{1}$ and ILONA LINNOILA, M.D. ${ }^{2}$
}

\begin{abstract}
SEPPÄLÄINEN, A. M. and LINNOILA, I. Electrophysiological studies on rabbits in long-term exposure to carbon disulfide. Scand. $j$. work environ. \& health 1 (1975) 178-183. Electroneuromyography was performed as part of a multidimensional study of experimental carbon disulfide poisoning of rabbits. Ten rabbits were exposed by inhalation to $750 \mathrm{ppm}$ of carbon disulfide for 6 hours a day, 5 days a week for 10 weeks. A slowing of the mator conduction velocity of the sciatic nerve was clearly observable during the course of exposure. This slowing preceded clinical paralysis, which became severe in the hind limbs within 9 weeks. Although the amplitude of the motor response to stimulation diminished markedily towards the end of the exposure period, a response of about $2 \mathrm{mV}$ was always elicitable. Definite fibrillations could be noted in the gastrocnemius muscle of the rabbits after exposure for 9 weeks. In the two rabbits allowed to recover, the fibrillations continued for up to 2 months after the cessation of the carbon disulfide exposure. As the paralysis was very severe, even though the nervous conductivity was rather well preserved, it was assumed that a lesion at the spinal cord level was combined with neuropathy. These experimental findings from rabbits agreed well with results from clinical studies of workers occupationally exposed to carbon disulfide. Some similarities, but also differences, were observable between neurophysiological findings in carbon disulfide and other forms of experimental toxic neuropathy.
\end{abstract}

Key words: carbon disulfide, neuropathy, rabbits, electroneuromyography.

Polyneuropathy is a conspicuous clinical symptom of chronic carbon disulfide $\left(\mathrm{CS}_{2}\right)$ poisoning. Some electrophysiological tests were incorporated in experimental studies on $\mathrm{CS}_{2}$ toxicology as early as 1941 (8), and stimulation electromyography has subsequently been applied in animal experiments (11).

For a number of years at the Institute of Occupational Health in Finland, electroneuromyography has been employed in the investigation of chronic $\mathrm{CS}_{2}$ poisoning in human beings (14). In occupational exposure to $\mathrm{CS}_{2}$ there are often coexisting

1 Department of Occupational Medicine, Institute of Occupational Health, Helsinki, Finland.

2 Department of Neurology, University of Helsinki, Finland

Reprint requests to: Dr. Anna Maria Seppäläinen, Institute of Occupational Health, Haartmaninkatu 1, FIN-00290 Helsinki 29, Finland. factors, such as concomitant exposure to hydrogen sulfide and possible alcohol consumption, which make the specific effects of $\mathrm{CS}_{2}$ difficult to assess with exactitude.

For a study of the development of neuropathy purely under the influence of $\mathrm{CS}_{2}$, we have included electroneuromyography of rabbits in a multidisciplinary study of experimental $\mathrm{CS}_{2}$ poisoning. The assumption was made that electrophysiological changes would precede clinical deficiencies and would thus provide indications of the course and the outcome of $\mathrm{CS}_{2}$ neuropathy, with help in the determination of the timing of neuropathological and neurochemical studies, which will be reported separately.

The results obtained in electrophysiological studies of rabbits subjected to longterm exposure to carbon disulfide are presented in this report. 


\section{MATERIALS AND METHODS}

\section{Animals}

The animals used were 14 male New Zealand white rabbits, weighing $2,100-3,600 \mathrm{~g}$ at the beginning of the experiment. They were kept singly in wire cages, fed a standard commercial diet (Orion Oy, Helsinki, Finland) with a crude protein content of $19 \%$, and allowed to drink tap water. Their condition was examined daily during the experiment, and they were weighed once a week.

\section{Exposure}

Ten rabbits were exposed by inhalation to a $\mathrm{CS}_{2}$ concentration of $750 \mathrm{ppm}$ for 6 hours a day, 5 days a week. Nine were exposed for 10 weeks, but one had to be sacrificed after exposure for 8.5 weeks because it refused to eat or drink. Four rabbits served as a control group with respect to feeding and living conditions. Two of the exposed rabbits were allowed to recover for 14 weeks.

The rabbits were placed, in their individual cages, within a tiled, air-tight exposure chamber, $9.47 \mathrm{~m}^{3}$ in cubic content. All organic material, including the food, was removed at the beginning of the daily exposure. Free access was given to tap water. Carbon disulfide was evaporated in a stream of nitrogen into the chamber. Continuous atmospheric mixing was effected by an electric fan. The $\mathrm{CS}_{2}$ concentration was maintained at a steady rate by hourly measurements, with small amounts of $\mathrm{CS}_{2}$ being added as required. Hourly checks were made to ensure that the oxygen concentration stayed normal $(21 \pm 0.5$ vol $\%)$ throughout the exposure. The concentration of carbon dioxide was kept at $0.2-0.3 \mathrm{vol} \%$.

\section{Neurophysiological methods}

The motor conduction velocity (MCV) of the sciatic nerve was measured as follows: The nerve was stimulated by supramaximal square wave pulses $0.2 \mathrm{~ms}$ in duration, from a Disa Ministim, with a bipolar skin electrode (Disa 13K62) midway between the hip and knee joints. The muscle response was picked up by means of a coaxial needle electrode, inserted in the gastrocnemius muscle, and amplified with a two-channel Disa electromyograph (fig. 1). The delay from the stimulus to the beginning of the first deflection was read directly from the time scale unit of the device. On occasion the response was photographed with a Polaroid camera. The MCV was calculated by division of the distance between the stimulating electrode and the recording electrode by the latency. No correction was made for the terminal delay in the myoneural junction, as it was assumed that this delay remained on a similar level throughout the study period. The MCVs of all the rabbits were measured before and during exposure; in general, two monthly measurements were obtained of each. The measurements were made 30 to $60 \mathrm{~min}$ after the daily exposure at midweek. Two rabbits were saved for a recovery period of 14 weeks, during which monthly MCV measurements were made in the afternoons. Electromyographic examination during muscle relaxation, and thus the observation of spontaneous activity, was practicable from the third month of $\mathrm{CS}_{2}$ exposure to the third month of recovery. Seven MCV measurements were also made of four control animals.

\section{RESULTS}

During the first week of exposure the rabbits seemed to be very tired and sleepy and did not make any spontaneous movements for about 2 hours after the daily exposure. Later on they recovered rapidly after the daily exposure had been stopped.

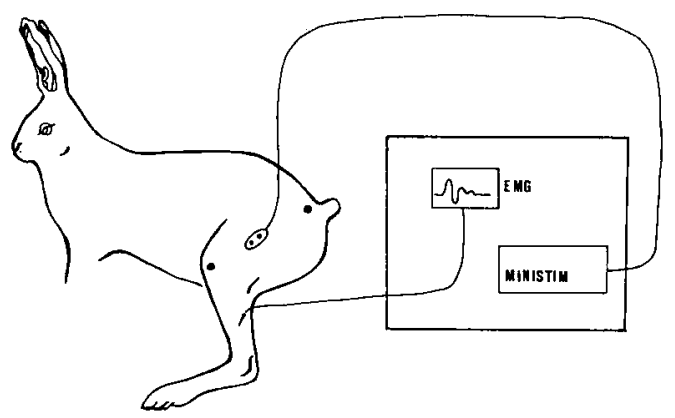

Fig. 1. Experimental arrangement for measurement of the motor nerve conduction velocity of a rabbit. 
In the chamber the animals were normally alert unitil the sixth (and last) hour of $\mathrm{CS}_{2}$ inhalation, when they displayed signs of extreme tiredness. After 7 weeks two rabbits showed difficulties in using their hind legs. Two weeks later all of the rabbits showed a loss of control of the hind legs to a point at which the rear quarters were almost unable to support the body or to move with it.

During the first four weeks of exposure the rabbits continued to gain weight (fig. 2). Subsequently their weight began slowly to decrease, although it did not fall below the preexposure value.

The results obtained in the MCV measurements of the sciatic nerve of the ten rabbits exposed to $\mathrm{CS}_{2}$ are presented in fig. 3. The monthly means and standard deviations have been calculated on the basis of the mean MCV for each individual rabbit. Only the mean MCVs of the two remaining rabbits are indicated for the recovery period. The mean $\mathrm{MCV}$ of the ten rabbits before exposure was $39.6 \mathrm{~m} / \mathrm{s}$, with a standard deviation of 9.4 , and that of the four control rabbits was $43.1 \mathrm{~m} / \mathrm{s}$ with a standard deviation of 8.0. A steady decline became apparent in the mean MCV of the exposed rabbits. During the first month of exposure a mean slowing of 8 $\mathrm{m} / \mathrm{s}$ from the preexposure value $(t=2.31$, $\mathrm{p}<0.05$ ) was noted. During the second and third months of exposure the slowing continued; the mean slowing, as compared to the mean of preexposure MCVs, amounted to 17 and $19 \mathrm{~m} / \mathrm{s} \quad(t=4.59$, $\mathrm{p}<0.01$, and $\mathrm{t}=13.16, \mathrm{p}<0.001)$, respectively. Before exposure, and during the

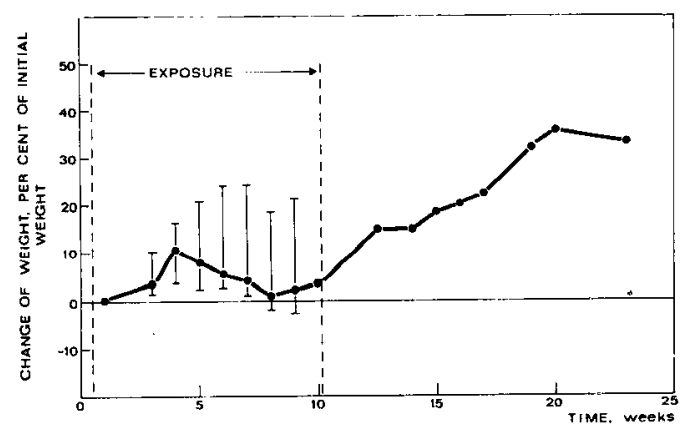

Fig. 2. Change of weight in rabbits during and after $\mathrm{CS}_{2}$ exposure as a percentage of the initial weight.

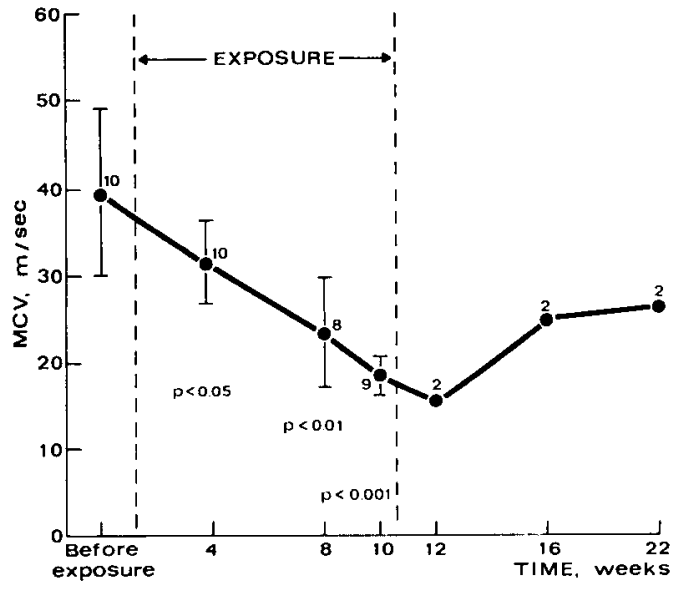

Fig. 3. Motor nerve conduction velocity of rabbits during and after $\mathrm{CS}_{2}$ exposure. The figures indicate the number of rabbits studied at the given time.

first six weeks of exposure, the amplitude of the motcr response averaged $10 \mathrm{mV}$ (fig. 4). A gradual diminution in the amplitude then became noticeable, and after 10 weelks of exposure the amplitude averaged only $2 \mathrm{mV}$ (fig. 5).

After exposure was stopped, a tendency towards improving MCV values was observed in the two remaining rabbits during the second month of recovery.

After 9 weeks of exposure eight of the ten rabbits displayed definite fibrillations (fig. 6) in the EMG of the gastrocnemius muscle. One week later fibrillations were found in the other two rabbits. Denervation potentials were thus noted in all of the rabbits during the third month of exposure to $\mathbf{C S}_{2}$. At that time voluntary electromyographic activity was scarce in the gastrocnemius muscle of all the rabbits. Observations of fibrillation continued for 2 months after the cessation of exposure. When 3 months had passed since exposure, no further fibrillations were discernible; at that time, voluntary muscle activity was quite abundant so that muscular relaxation could not be achieved.

\section{DISCUSSION}

It was decided that the rather high concentration of $750 \mathrm{ppm} \mathrm{CS}_{2}$ would be used on the basis of a pilot study, in which a 


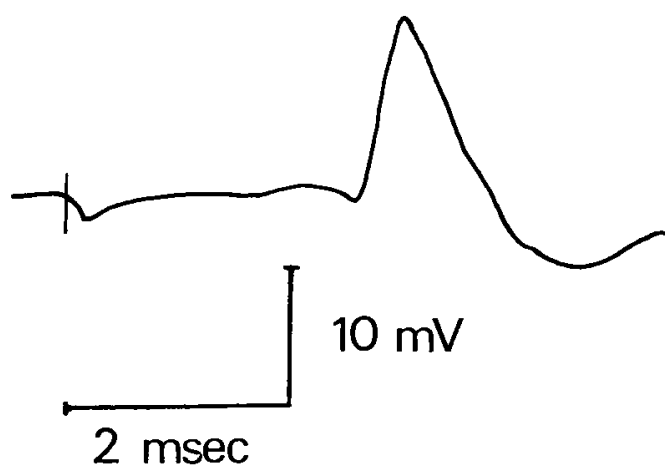

Fig. 4. Motor response to stimulation of the sciatic nerve at the beginning of $\mathrm{CS}_{2}$ exposure.

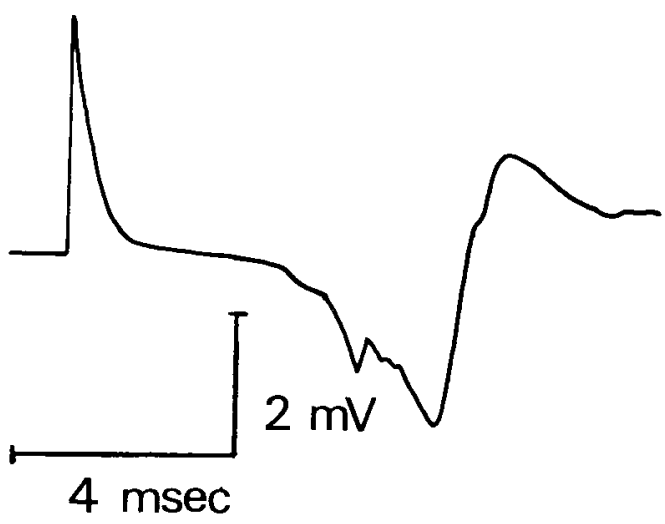

Fig. 5. Motor response to stimulation of the sciatic nerve after $\mathrm{CS}_{2}$ exposure for 10 weeks. (Note the different time scale and amplication as compared to fig. 4)
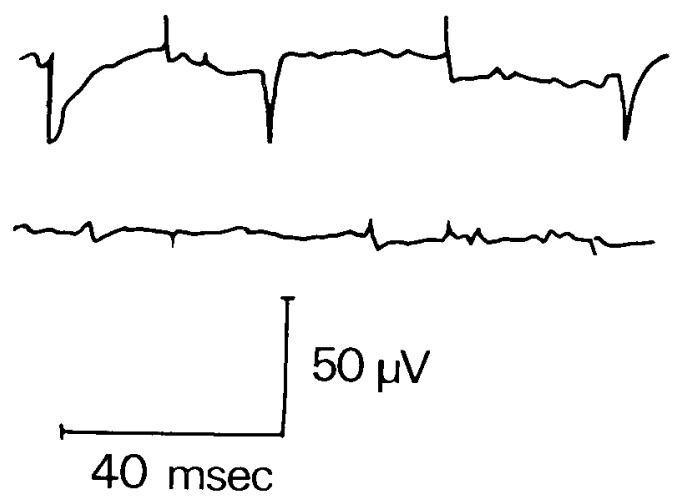

Fig. 6. Fibrillations and positive monophasic potentials in the gastrocnemius muscle of a rabbit exposed to $\mathrm{CS}_{2}$ for 9 weeks. higher concentration induced excessive acute toxicity and $500 \mathrm{ppm}$ did not appear to exert any effect. According to Cohen et al. (2), 500 to $750 \mathrm{ppm}$ seemed to be the toxic threshold concentration of $\mathrm{CS}_{2}$ in an experimental exposure by inhalation. Moreover, $750 \mathrm{ppm}$ was also equivalent to the concentration of $2.4 \mathrm{mg} / \mathrm{l}$ of $\mathrm{CS}_{2}$ utilized by Lukáš (11) in his experimental series of rats.

During the first week of exposure the rabbits were rather lethargic during and immediately after exposure - as a manifestation of acute toxicity, $\mathrm{CS}_{2}$ has a certain narcotic effect (3). Subsequently, the rabbits displayed tiredness only during the sixth hour of exposure, at the time when the equilibrium of $\mathrm{CS}_{2}$ in the tissues is reached (1).

$A$ clear slowing of the $\mathrm{MCV}$ of the sciatic nerve was noted in rabbits during longterm exposure to $750 \mathrm{ppm}$ of $\mathrm{CS}_{2}$. Marked slowing in the MCV was observed even before clinical paralysis. On the appearance of alinical paralysis in the hind limbs, all of the rabbits displayed fibrillations in the gastrocnemius muscle as signs of denervation. During the recovery period improvement was noted in the MCVs of both the surviving rabbits, although during a period of 3 months the MCV of neither rabbit reached its preexposure level.

These findings are consistent with peripheral neurogenic lesions, and in particular with peripheral neuropathy. Demyelinating processes induce a slowing of the $\mathrm{MCV}$, but extensive axonal degeneration can exercise the same effect. It has to be assumed that, in addition to neuropathy, damage also existed at the spinal cord level, as the paralysis was severe and the lack of voluntary motor unit potentials, almost total. Furthermore, the good electrical excitability that remained and the rather well-preserved conductivity of the nerve - the amplitude of the motor response diminished, but a clear response of ample magnitude remained until the end of the experiment - suggest lesions other than just segmental demyelination as a pathological basis for the clinical paralysis. Indeed, preliminary results obtained in neuropathological studies by our team have shown severe morphological alterations in the lateral and anterior 
funiculi of the spinal cord in addition to pronounced axonal alterations in peripheral nerves (9).

Lukáš (11) has demonstrated a similar slowing of the nerve conduction velocity in rats at a similar exposure level. He also showed an improvement in MCV within 3 months after long-term $\mathrm{CS}_{2}$ exposure had been stopped. Lukás has suggested that the basic lesions were segmental demyelination, without convincing histological data. In another experiment marked slowing in the MCV of rats occurred in 5 weeks of hexachlorophene poisoning, but the $\mathrm{MCV}$ returned to normal as soon as 1 week after hexachlorophene feeding had ended (6). The authors suggested that occasional demyelinated nerve segments or "leaky" myelin caused the reduced MCV. More recently, Pleasure et al. (13) reported widespread intramyelinic vacuolization, segmental demyelination, and widening of the nodes of Ranvier in the nerves of rats which had been fed hexachlorophene.

Experimental acrylamide neuropathy has been the subject of more extensive study. Common features of neurophysiological studies have included the clear slowing of nerve conduction velocities. Concomitantly the elicited muscle action potentials have usually been greatly reduced in amplitude, as has been demonstrated in cats and monkeys (7) and baboons (5). In the baboon the reduction of response amplitude was found to be severe; finally the response disappeared altogether to reappear only after a very long period of recovery. In pathological studies the authors found complete degeneration in the distal parts of the fibers, and only some paranodal demyelination (5). Severe degeneration of both axons and myelin, predominantly in distal portions of the nerves, has been reported in acrylamide neuropathy particularly as regards rats $(4,15)$, but also cats (7).

In some aspects neurophysiological findings in acrylamide neuropathy differ from $\mathrm{CS}_{2}$ neuropathy. For instance, the marked reduction in motor response reported in acrylamide neuropathy was not noted in the present study. A similar slowing of the $\mathrm{MCV}$, without any reported reduction in muscle action potential amplitude, occurred in hexachlorophene poisoning, but quick recovery, as that from hexachlorophene neuropathy, was lacking in $\mathrm{CS}_{2}$ neuropathy. The differences may be based not only upon the different chemical nature of the causative agent but also upon the acuteness of the poisoning. At an early stage either segmental demyelination or axonal degeneration may predominate, while at a later stage both types of degeneration occur, one secondary to the other (16). In the case of $\mathrm{CS}_{2}$ neuropathy the neuropathologically confirmed spinal cord lesion also modifies the electrophysiological findings.

Long-term $\mathrm{CS}_{\mathrm{g}}$ exposure also induces neuropathy and the slowing of nerve conduction velocities in industrial workers $(10,12,14,17)$. In long-standing human $\mathrm{CS}_{2}$ poisoning, lesions at the spinal cord level have been suggested (14). Our experimental findings with the rabbit are in close agreement with those found in human $\mathrm{CS}_{2}$ exposure. They prove that $\mathrm{CS}_{2}$ alone is fully capable of producing neuropathy, and no concomitant exposure to $\mathrm{H}_{2} \mathrm{~S}$ or alcohol consumption is needed.

\section{REFERENCES}

1. BRIEGER, H. Carbon disulphide in the living organism: Retention, biotransformation, and pathophysiologic effects. In: H. BRIEGER and J. TEISINGER (eds), Toxicology of carbon disulphide. Excerpta Medica Foundation, Amsterdam $1967 \mathrm{pp}$. $27-31$.

2. COHEN, A. E., SCHEEL, L. D., KOPP, J. F., STOCKELL, F. R., KEENAN, R. G., MOUNTAIN, J. T. and PAULUS, H. J. Biochemical mechanisms in chronic carbon disulfide poisoning. Am. ind. hyg. assoc. $j$. 20 (1959) 303-323.

3. DAVIDSON, M. and FEINLEIB, M. Carbon disulfide poisoning: A review. Am. heart $j$. 83 (1972) 100-112.

4. FULLERTON, P. M. and BARNES, J. M. Peripheral neuropathy in rats produced by acrylamide. $B r . j$. ind. med. 23 (1966) $210-$ 221.

5. HOPKINS, A. P. and GILLIATT, R. W. Motor and sensory conduction velocity in the baboon: Normal values and changes during acrylamide neuropathy. J. neurol. neurosurg. psychiatry 34 (1971) 415-426.

6. DE JESUS, P. V. Jr. and PLEASURE, D. E. Hexachlorophene neuropathy. Arch. neurol. 29 (1973) $180-182$.

7. LESWING, R. J. and RIBELIN, W. E. Physiologic and pathologic changes in acrylamide neuropathy. Arch. environ. health 18 (1969) 22-29.

8. LEWEY, F. H. Experimental chronic 
carbon disulfide poisoning in dogs: A clinical, biochemical and pathological study. J. ind. hyg. \& toxicol. 23 (1941) 415-436.

9. LINNOILA, I., HALTIA, M., SEPPÄLÄINEN, A. IM. and PALO, J. Experimental carbon disulphide poisoning: Morphological and neurophysiological studies. Paper read at the VIIth international congress of neuropathology. Budapest, Sept. 1-7 1974.

10. LUKÁS, E. Leitgeschwindigkeit peripherer Nerven bei Schwefelkohlenstoff ausgesetzten Personen. Int. j. clin. pharmacol. ther. \& toxicol. 2 (1969) 354-358.

11. LUKÁS, E. Stimulation electromyography in experimental toxicology (Carbon disulphide neuropathy in rats.). Med. lav. 61 (1970) 302-308.

12. MANU, P., LILIS, R., LANCRANJAN, I., IONESCU, S. and VASILESCU, I. The value of electromyographic changes in the early diagnosis of carbon disulphide peripheral neuropathy. Med. lav. 61 (1970) 102-108.

Received for publication: 1975-03-19
13. PLEASURE, D., TOWFIGHI, J., SILBERBERG, D. and PARRIS, J. The pathogenesis of hexachlorophene neuropathy: In vivo and in vitro studies. Neurology (Minneap.) 24 (1974) 1068-1075.

14. SEPPÄLÄINEN, A. M., TOLONEN, M., KARLI, P., HANNINEN, H. and HERNBERG, S. Neurophysiological findings in chronic carbon disulfide poisoning: A descriptive study. Work-environ.-health 9 (1972) $71-75$.

15. SUZUKI, K. and PFAFF, L. Acrylamide neuropathy in rats. Acta neuropathol. (Berl.) 24 (1973) 197-213.

16. THOMAS, P. K. The morphological basis for alterations in nerve conduction in peripheral neuropathy. Proc. r. soc. med. 64 (1971) 295-298.

17. VASILESCU, C. Motor nerve conduction velocity and electromyogram in carbon disulphide poisoning. Rev. roum. neurol. 9 (1972) $63-71$. 